\title{
The Mediating Role of Purchase Intention Toward Purchase Decision of Xiaomi Mobile
}

\author{
Amiril Azizah ${ }^{1}$, Muhammad Kiswanto ${ }^{2}$, Armini Ningsih ${ }^{3}$, Uswatun Hasanah ${ }^{4}$ \\ \{amirilazizah@polnes.ac.id $\left.{ }^{1}\right\}$ \\ Department of Business Administration, Polytechnic State of Samarinda ${ }^{1,2,3,4}$
}

\begin{abstract}
The purpose of this study is to analyze and prove the effect of Perceived Value on Purchase Intention on Xiaomi Mobile.The data were obtained from 145 Xiaomi mobile users in Indonesia. This research uses the sampling technique of Accidental Sampling. Data from respondents were tabulated and tested using statistical methods. Data has been tested for their level of validity and reliability. Results of the test instruments of the research questions were declared valid and reliable. Based on the results that have been done, it can be concluded that Perceived Value, country of origin, product quality, have a significant effect on Purchase Intention on Xioami Mobile. Meanwhile, price and product quality have no significant effect on purchase intention on Xiaomi Mobile. Perceived value has no significant impact on the purchase decision on Xiaomi mobile. Price, country of origin, and product quality have the significant impact on purchase decision on Xiaomi mobile.
\end{abstract}

Keywords: Perceived value, price, brand image, country of origin, purchase intention, purchase intention

\section{Introduction}

The development of digital technology is making lifestyle changes. Communication tools are essential such as mobilephone. Indonesia Smartphone users have increased every year. Several cellphone brands competing in this business in Indonesia include: Samsung, Apple, Huawei, Xiaomi, Lenovo and many more. This situation causes intense competition among competitors in the telecommunications sector. The Xiaomi brand has been known to the Chinese public since 2011, began to be known to the Indonesian public in 2013 and began to be attracted to the market in 2014. Xiaomi phones use an Android operating system that users are familiar with with various features. Xiaomi is sold at low prices and luxurious specifications thus, that it becomes a consumer attraction.

The problems are: 1) Does Perceived Value have a significant effect on Purchase Intention on Xiaomi mobile phone? 2) Does Perceived Value have a significant effect on Purchase Intention on Xiaomi mobile 3) Does Brand Image have a significant effect on Purchase Intention on Xiaomi mobile? 4) Does the Country of Origin have a significant effect on Purchase Intention on Xiaomi mobile phone? 5) Does Product Quality have a significant effect on Purchase Intention on Xiaomi mobile? 6) Does Perceived Value have a significant effect on Purchase Decision on Xiaomi mobile phone? 7) Does Price have a significant effect on Purchase Decision on Xiaomi mobile phone? 8) Does Brand Image have a significant effect on Purchase Decision 
on Xiaomi mobile phone? 9) Does the Country of Origin have a significant effect on Purchase Decision on Xiaomi mobile phone? 10) Does Product Quality have a significant effect on Purchase Decision on Xiaomi Brand mobile phone? 11) Does Purchase Intention have a significant effect on Purchase Decision on Xiaomi mobile phone?

\section{Theoritical Background}

Dodds et al. [1] suggest that perceived value relate to the perception of customers on value in the trade off among the perceived quality which is relate to the perceived sacrifice from the paying of price. Zeithaml [6] stated that perceived value describes the utilities of the product when the customer has benefit for paying of the cost. Kotler [2], price refer to advantage of product or service by the customers when the pay of money. Swastha \& Irawan describe of price is the amount of money to receive some products or when the customer has service. Price refer to the customer to get some product or service have to pay with amount of money. Kotler and Keller [4] define brand image as the reflection of the product by the customer. It relates to the memoris by the customer on product. Then, country-of-origin relate to the where the product come from and brand of product. Moreover, country of origin as describe the product on the country as image before the customer buy or use some product. Kotler and Keller [4] added that product quality refer to facilities of the product including of the feature and characteristic as the capabilities of expectation by the customers.

Purchase Intention relate to the implementation of purchasing decisions from customers related to purchasing decisions. Schiffman and Kanuk [5] stated that purchase intention as the motivation of customer to get something to buy. Kotler and Armstrong [3] argue that the consumer buying decision process is a systematic way of looking at how a consumer makes the decision to purchase a product (any product) in a product category. Zaichowwsky understands involvement as “A person's perceived relevance of the object based on inherent needs, values and interests.

\section{Methods}

Data were collected from the accidental sampling method with a sample size of 168 respondents. Spread a list of questions in the form of statements with a Likert scale. Sugiyono (2010: 132) with five levels of answers, which is a scale of ordinal types from 1 (one) which shows strongly disagree to 5 (five) which indicates strongly agree.

\section{Results and Discussion}

Based on the results of statistical tests using AMOS software, the p-value or probability value between the Perceived Value variable and the Purchase Intention variable is 0.009 , which means it is smaller than the specified error rate of 0.050. Or the Critical Ratio (C.R.) value is greater than 1.96 which is determined from the table if the research data uses a number of respondents more than 100. Critical Ratio (C.R.) variable Perceived Value to the Purchase 
Intention variable is 2,600 it indicates the value of C.R. greater than the critical value is 1.96 . This shows that the Perceived Value has a significant positive effect on the Purchase Intention. The strongest of Perceived Value indicator is Quality with a Loading Factor value of 0.643, while the Purchase Intention variable, has an indicator of referential interest with loading factor is 0.792 , greater than the error term value of 0.5 . The Perceived Value has a significant positive effect on the Purchase Intention. It is reflected in the Reference Interest indicator for Xiaomi mobile phone users. This means that the value of a person's profit will arise because of the qualities possessed by users of Xiaomi mobile phone. Thus, respondents will look for references about Xiaomi mobile that appear because of a sense of intention to buy using Xiaomi mobile. Conceptual framework showed on Figure 1.

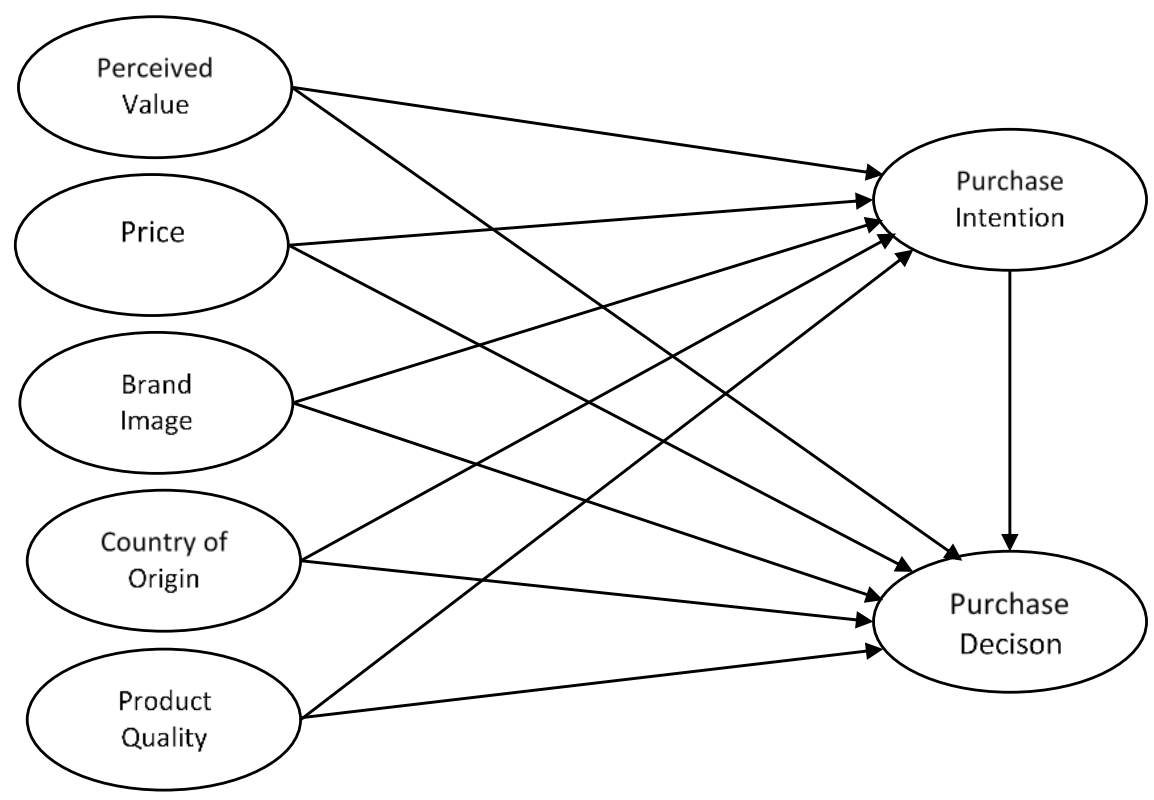

Fig. 1. Conceptual framework

The result of the coefficient between Price and Purchase Intention shows a positive direction with a value of 0.555 it means the level of closeness of the relationship between the Brand Image and Purchase Intention. Based on the results p-value or probability value between the Price variable and the Purchase Intention variable is 0.555 , which means that it is greater than the specified error rate of 0.050 . Or the Critical Ratio (C.R.) value is less than 1.96 which is determined from the $t$ table if the research data uses more than 100 respondents. The Critical Ratio (C.R.) of the Brand Image variable to the Purchase Intention variable is -0.591 which means the value of C.R. smaller than the critical value which is equal to 1.96 . This shows that the Price variable has a positive and insignificant effect on the Purchase Intention variable.

The indicator the strongest Price variable is the reasonable indicator with a loading factor value of 0.823 , greater than the error term, which is 0.5 . It indicates that $r$ as appropriate a measure of Price.While the Purchase Intention, has an indicator of referential interest as a reflection of the Purchase Intention variable, this is because the Referential Interest indicator has the greatest Loading Factor value than the other indicators, which is 0.792 , greater than the error term value of 0.5 . 
The Price variable which is reflected in the Reasonable indicator does not have a significant effect on the Purchase Intention. It is reflected in the Reference Interest indicator for Xiaomi mobile phone users. This means that user judges the price level of Xiaomi mobile phone because of have good price compared to other brands. It means that the price level has little influence on user responses when choosing Xiaomi mobile is the right choice.

Based on the results, the p-value or probability value between the Brand Image variable and the Purchase Intention variable is 0.048 , it is smaller than the specified error rate of 0.050 . Or the Critical Ratio (C.R.) value is greater than 1.96 which is determined from the table if the research data uses more than 100 respondents. Critical Ratio (C.R.) variable Perceived Value to the Purchase Intention variable is -1.974 which means the value of C.R. greater than the critical value which is equal to 1.96 . This shows that the Perceived Value has a significant positive effect on the Purchase Intention

The strongest status of the Brand Image variable is the indicator with a Loading Factor value of 0.954 , greater than the error term, which is 0.5 . While the affected variable, namely the Purchase Intention variable, has an indicator of referential Interest as a reflection of the Purchase Intention variable, because the Referential Interest indicator has the greatest Loading Factor value than the other indicators, which is 0.792 , greater than the error term value of 0.5 .

The Brand Image is reflected in the nice indicator has a significant effect on the Purchase Intention. This means that the value of the brand image will emerge because the Xiaomi mobile is a good brand. User respondents know that the Xiaomi mobile is not with a good image but with sufficient quality, the capacity needed at a price that is not too expensive. The user will look for references about the Xiaomi mobile then a sense of intention to buy Xiaomi mobile.

Based on the results the p-value or probability value between the Country-of-Origin variable and the Purchase Intention variable is 0.047 which means it is smaller than the specified error rate of 0.050 . Or the Critical Ratio (C.R.) value is greater than 1.96 which is determined from the $t$ table if the research data uses more than 100 respondents. The Critical Ratio (C.R.) of the Country of Origin variable to the Purchase Intention variable is 1.990 which means the value of C.R. greater than the critical value which is equal to 1.96. Country of Origin variable has a significant positive effect on the Purchase Intention variable.

The strongest indicator from the Country of Origin is the Excellent indicator with a Loading Factor value of 0.776 , greater than the error term, which is 0.5 . Excellent indicator has a level of truth as a measure of the Country-of-Origin variable, it means that the Country Of Origin is reflected in the Excellent indicator. While the affected variable, namely the Purchase Intention variable, has an indicator of Referential Interest as a reflection of the Purchase Intention variable, this is because the Referential Interest indicator has the greatest Loading Factor value than the other indicators, which is 0.792 , greater than the error term value of 0.5 . Country of Origin has a significant effect on the Purchase Intention. It means customer perception that the country of origin for the production of Xiaomi mobile is a good product.

Product Quality and Purchase Intention shows a positive direction with a value of 0.360 which means the level of closeness of the relationship between the Product Quality variable to Purchase Intention. Based on the results, the p-value or probability value between the Product Quality variable and the Purchase Intention variable is 0.360 , which means it is greater than the specified error rate of 0.050 . Or the Critical Ratio (C.R.) value is less than 1.96 which is determined from the $t$ table if the research data uses more than 100 respondents. The Critical Ratio (C.R.) of the Product Quality variable to the Purchase Intention variable is 0.915 which means the value of C.R. smaller than the critical value which is equal to 1.96 . This shows that the Price variable has no significant effect on the Purchase Intention variable. 
The strogest indicator is Product Quality with a loading factor value of 0.812, greater than the error term, which is 0.5 . While the affected variable, namely the Purchase Intention variable, has an indicator of Referential Interest as a reflection of the Purchase Intention variable, this is because the Referential Interest indicator has the greatest Loading Factor value than the other indicators, which is 0.792 , greater than the error term value of 0.5. The Product Quality variable which is reflected in the Features indicator has no significant effect on the Purchase Intention variable which is reflected in the Reference Interest indicator for Xiaomi mobile. This means the quality of Xiaomi mobile products because of good features compared to other product. This indicates the company's image has little effect on one's satisfaction to the customer.

The relationship between Perceived Value and Purchase decision is a positive with a value of 0.571 , it is greater than the specified error rate of 0.050 . Or the Critical Ratio (C.R.) value is less than 1.96 which is determined from the $t$ table if the research data uses more than 100 respondents. Critical Ratio (C.R.) variable Perceived Value to the Purchase Decision variable is -0.566 which means the value of C.R. smaller than the critical value which is equal to 1.96 . This shows that the perceived value variable has a positive and insignificant effect on the Purchase decision variable.

The indicator that has the strongest status from the Perceived Value variable is the Quality Functional indicator with a Loading Factor value of 0.643, greater than the error term, which is 0.5. This shows that the Quality Functional indicator has a level of truth as a measure of the Perceived Value variable, which means that the Perceived Value variable is reflected in the Quality Functional indicator. While the variable that is influenced, namely the Purchase Decision variable has a Product Quality indicator as a reflection of the Purchase Decision variable, this is because the Product Quality indicator has the largest Loading Factor value than the other indicators, which is 0.540 , which is greater than the error term value of 0.5 . It indicates that perceived value will be influence to the customer on purchase decision.

The parameter coefficient between Price and Purchase decision is a positive with $\mathrm{P}$ value of 0.452. It is greater than the specified error rate of 0.050. The Critical Ratio (C.R.) of the Price variable to the Purchase decision variable is 0.753 which means the value of C.R. smaller than the critical value which is equal to 1.96 . This shows that the Price variable has no significant positive effect on the Purchase Decision variable.

The indicator that has the strongest status of the Price variable is the Reasonable indicator with a Loading Factor value of 0.823 , greater than the error term, which is 0.5 . This shows that the Reasonable indicator has a level of truth as a measure of the Price variable, which means that the Price variable is reflected in the Reasonable indicator. While the variable that is influenced, namely the Purchase Decision variable has a Product Quality indicator as a reflection of the Purchase Decision variable, this is because the Product Quality indicator has the largest Loading Factor value than the other indicators, which is 0.540 , which is greater than the error term value of 0.5 .

Brand Image variable and the Purchase Intention variable has p value is 0.045 , it is smaller than the specified error rate of 0.050. Or the Critical Ratio (C.R.) value is greater than 1.96 which is determined from the $t$ table if the research data uses the number of respondents more than 100. Critical Ratio (C.R.) variable Perceived value to the purchase intention variable is 2.006 which means the value of C.R. greater than the critical value which is equal to 1.96 . It is shown the brand Image has a significant positive effect on the Purchase decision.

The indicator that has the strongest status of the Brand Image variable is the nice indicator with a Loading Factor value of 0.954, greater than the error term, which is 0.5 . This shows that the Nice indicator has a level of truth as a measure of the Brand Image variable by $75 \%$, which means that the brand Image variable is reflected in the nice indicator. While the variable that is 
influenced, namely the Purchase Decision variable, has a Product selection indicator as a reflection of the Purchase Decision variable, this is because the Product Selection indicator has the largest Loading Factor value than the other indicators, which is 0.540 , which is greater than the error term value of 0.5 .

Based on the results, the p-value between the Country of Origin and the Purchase Decision is 0.036 and it is smaller than the specified error rate of 0.050. Or the Critical Ratio (C.R.) value is greater than 1.96 which is determined from the $\mathrm{t}$ table if the research data uses the number of respondents more than 100. Critical Ratio (C.R.) of the Country-of-Origin variable to the Purchase Decision variable is -2.102 which means the value of C.R. greater than the critical value which is equal to 1.96 . This shows that the country-of-origin variable has a significant positive effect on the Purchase Decision variable.

The indicator strongest status from the Country-of-Origin variable is the Excellent indicator with a Loading Factor value of 0.776 , greater than the error term, which is 0.5 . This shows that the excellent indicator has a level of truth as a measure of the Country-of-Origin variable. Country Of Origin variable is reflected in the Excellent indicator. While the variable that is influenced, namely the Purchase Decision variable has a Product Quality indicator as a reflection of the Purchase Decision variable, this is because the Product Quality indicator has the largest Loading Factor value than the other indicators, which is 0.540 , which is greater than the error term value of 0.5 . The country-of-origin variable which is reflected in the excellent indicator has a significant positive effect on the Purchase decision as reflected in the Product selection indicator for Xiaomi mobile.

The relationship between Product Quality and Purchase decision has p value is 0.375 . it is greater than the specified error rate of 0.050 . Or the Critical Ratio (C.R.) value is less than 1.96 which is determined from the $t$ table if the research data uses more than 100 respondents. The Critical Ratio (C.R.) of the Brand Image variable to the Purchase Intention variable is 0.887 . It means the value of C.R. smaller than the critical value is equal to 1.96 . This shows that the Product Quality variable has a negative and insignificant effect on the Purchase Decision variable.

The Product Quality variable which is reflected in the Features indicator has a negative and insignificant effect on the Purchase decision which is reflected in the Product Selection indicator for Xiaomi mobile. This means that user Xiaomi mobile looking at the features of product to make decision to buy.

The result of the parameter coefficient between Purchase Intention and Purchase Decision shows a positive direction with a value of $0.000(* * *)$, which means that the level of closeness of the relationship between Purchase Intention and Purchase Decision variables is $52 \%$. The relationship between the Purchase Intention variable and the Purchase Decision variable has $\mathrm{p}$ value is 0.050 . Or the Critical Ratio (C.R.) value is greater than 1.96 which is determined from the $t$ table if the research data uses more than 100 respondents. The Critical Ratio (C.R.) of the Purchase Intention variable to the Purchase Intention variable is 3,890 which means the value of C.R. greater than the critical value which is equal to 1.96. This indicate that Purchase Intention has a significant positive effect on the Purchase decision

The indicator that has the strongest of the Purchase Intention variable is the referential interest indicator as a reflection of the Purchase Intention variable, this is because the referential interest indicator has the greatest Loading Factor value than the other indicators, which is 0.792 , greater than the error term value of 0.5 . While the variable that is influenced, namely the Purchase Decision variable has a Product Quality indicator as a reflection of the Purchase Decision variable, this is because the Product Quality indicator has the largest Loading Factor value than the other indicators, which is 0.540 , which is greater than the error term value of 0.5 . 
The Purchase Intention variable which is reflected in the Referential Interest indicator has a significant positive effect on the Purchase Decision variable which is reflected in the Product Selection indicator for Xiaomi brand cellphone users in Samarinda city. This means that an interest in buying someone that arises because of a sense of someone looking for references about Xiaomi mobile phone, will further increase one's strong intention to generate interest in buying in the future using Xiaomi mobile phone and user responses to choosing Xiaomi mobile are the right choice. In other words, the higher the interest in buying someone by looking for references about the Xiaomi mobile, the greater the influence of one's buying decision.

The results of this study indicate that the indirect effect of the variable Perceived Value on Purchase Decision through Purchase Intention has a coefficient value of 0.264 . When compared with the direct effect between the Perceived Value variable on Purchase Intention with the relationship path coefficient value of 0.093 , the indirect effect value is greater than the direct effect. This means that the value of the profits that exist in the Xioami mobile phone has a greater influence on the purchase decision if it is through the intention to buy first, compared to the direct effect on the purchase decision.

The results of this study indicate that the indirect effect of the variable Price on Purchase Decision through Purchase Intention has a coefficient value of 0.036 . When compared with the direct influence between the variable Price on Purchase Intention with the path coefficient value of 0.094 , the value of the indirect effect is greater than the direct effect. This means that the price value that exists on Xioami mobile has a greater direct influence on purchasing decisions on Xiaomi mobile in the community compared to the effect on purchasing decisions if through the intention of buying first.

The results of this study indicate that the indirect effect of the Brand Image variable on Purchase Decision through Purchase Intention has a coefficient value of 0.089. When compared with the direct effect between the Brand Image variable on Purchase Intention with a relationship path coefficient value of 0.296 , the value of the indirect effect is greater than the direct effect. This means that the value of the brand image on Xioami mobile has a greater direct effect on decisions.

The results of this study indicate that the indirect effect of the Country Of Origin variable on Purchase Decision through Purchase Intention has a coefficient value of -0.096 . When compared with the direct effect between the Country of Origin variable on Purchase Intention with the path coefficient value of -0.297 , the value of the indirect effect is greater than the direct effect. This means that the price value that exists on Xioami mobile has a greater direct influence on purchasing decisions on Xiaomi mobile in the community.

The results of this study indicate that the indirect effect of the Product Quality variable on Purchase Decision through Purchase Intention has a coefficient value of 0.204 . When compared with the direct influence between the Perceived Value variable on Purchase Intention with the relationship path coefficient value of 0.113 , the value of the indirect effect is greater when compared to the direct effect. This means that the product quality on Xioami mobile has a greater influence on purchasing decisions if through the intention to buy first, rather than its direct influence on purchasing decisions on Xiaomi mobile

The total effect of the Perceived Value variable on Purchase Decision through Purchase Intention was 5.28 and previously 0.264 which was obtained from the sum of the direct effect value of -0.093 with an indirect effect value of 0.358 . When viewed in terms of the total effect obtained, the value of the indirect effect is greater than the value of the direct effect. This means that buying interest in Xiaomi mobile users will be increase.

Furthermore, the total influence of the price variable on Purchase Decision through Purchase Intention is 5.26 and previously 0.036 which is obtained from the sum of the direct 
effect value which is 0.094 with an indirect effect value of 0.058 . When viewed in terms of the total effect obtained, the value of the direct effect is greater than the value of the indirect effect. This means that buying interest in Xiaomi mobile users is greatly influenced by the fairness of the price.

The magnitude of the total influence of the Brand Image variable on Purchase Decision through Purchase Intention is listed in table 5.26 and previously 0.089 which is obtained from the sum of the direct effect value, which is 0.296 with an indirect effect value of 0.207 . When viewed in terms of the total effect obtained, the value of the direct effect is greater than the value of the indirect effect. This means that buying interest in Xiaomi mobile users is greatly influenced by how well the Xiaomi mobile product is towards the brand image.

The total influence of the Country-of-Origin variable on Purchase Decision through Purchase Intention was 5.26 and previously 0.096 which was obtained from the sum of the direct effect value which was -0.297 with an indirect effect value of 0.201 . When viewed in terms of the total effect obtained, the value of the indirect effect is greater than the value of the direct effect. This means that buying interest in Xiaomi mobile is greatly influenced by how well the Xiaomi bmobile product is in the country of production.

The total influence of the Product Quality variable on Purchase Decision through Purchase intention was 5.26 and previously it was 0.204 which was obtained from the sum of the direct effect value which was 0.113 with an indirect effect value of 0.091 . When viewed in terms of the total effect obtained, the value of the indirect effect is greater than the value of the direct effect. This means that buying interest in Xiaomi mobile users is greatly influenced by the features ofered.

\section{References}

[1] Dodds, W. B., Monroe, K. B., \& Grewal, D. (1991). Effects Of Price, Brand, And Store Information On Buyers' Product Evaluations. Journal Of Marketing Research, 307-319.

[2] Kotler, P. (2003). Manajemen Pemasaran Edisi Kesebelas. Jakarta: Indeks Kelompok Gramedia.

[3] Kotler, P., \& Amstrong, G. (2012). Principle Of Marketing (14 Edition Ed.). New Jersey: Pearson Prentice Hall, Inc.

[4] Kotler, P., \& Keller, K. L. (2012). Marketing Management (14 Edition Ed.). New Jersey: Pearson Prentice Hall, Inc.

[5] Schiffman, L. G., \& Kanuk, L. L. (2007). Consumer Behavior (7th Edition). New Jersey: Prentice Hall.

[6] Zeithaml. (1988). 3 g Marketing on The Internet. Canada: Jim Hoskins. 